\title{
Synaptic Mechanisms Underlying Strong Reciprocal Connectivity between the Medial Prefrontal Cortex and Basolateral Amygdala
}

\author{
Justin P. Little and Adam G. Carter \\ Center for Neural Science, New York University, New York, New York 10003
}

The medial prefrontal cortex (mPFC) plays a critical role in the control of cognition and emotion. Reciprocal circuits between the mPFC and basolateral amygdala (BLA) are particularly important for emotional control. However, the neurons and synapses that link these brain regions remain largely unknown. Here we examine long-range connections between the mouse MPFC and BLA, using whole-cell recordings, optogenetics, and two-photon microscopy. We first identify two non-overlapping populations of layer 2 pyramidal neurons that directly project to either the BLA or contralateral mPFC. We then show that pyramidal neurons projecting to the BLA receive much stronger excitatory inputs from this same brain region. We next assess the contributions of both presynaptic and postsynaptic mechanisms to this cell-type and input-specific connectivity. We use two-photon mapping to reveal differences in both the synaptic density and subcellular targeting of BLA inputs. Finally, we simulate and experimentally validate how the number, volume, and location of active spines all contribute to preferential synaptic drive. Together, our findings reveal a novel and strong reciprocal circuit that is likely to be important for how the mPFC controls cognition and emotion.

\section{Introduction}

The medial prefrontal cortex (mPFC) helps control cognition and emotion (Goldman-Rakic, 1995; Miller, 2000; Fuster, 2001), as highlighted by its dysfunction in neuropsychiatric disorders (Egan and Weinberger, 1997). This ability depends on reciprocal circuits between the mPFC and other cortical and subcortical regions (LeDoux, 2000; Sotres-Bayon et al., 2012). Long-range interactions between the $\mathrm{mPFC}$ and basolateral amygdala (BLA) are particularly important for emotional control (Herry et al., 2008; Burgos-Robles et al., 2009). In principle, these interactions could occur through indirect networks involving several brain regions or cortical layers, or via direct communication between neurons in the mPFC and BLA. However, little is known about the projection neurons and synaptic connections that might constitute these reciprocal circuits.

Pyramidal neurons in the mPFC are capable of sending diverse long-range outputs to other brain regions. The targets of layer 5 (L5) pyramidal neurons include the contralateral mPFC (cmPFC), striatum, and pons (Morishima and Kawaguchi, 2006; Dembrow et al., 2010; Morishima et al., 2011; Otsuka and Kawaguchi, 2011). As in other cortical areas, these projection neurons

\footnotetext{
Received June 5, 2013; revised July 25, 2013; accepted Aug. 8, 2013.

Author contributions: J.P.L. and A.G.C. designed research; J.P.L. performed research; J.P.L. analyzed data; J.P.L. and A.G.C. wrote the paper.

This work was supported by National Institutes of Health Grant R01-MH085974 (A.G.C.). We thank members of the Carter laboratory for helpful discussions and comments on this manuscript.

The authors declare no competing financial interests.

Correspondence should be addressed to Adam G. Carter, Center for Neural Science, New York University, 4 Washington Place, New York, NY 10003. E-mail: adam.carter@nyu.edu.

DOI:10.1523/JNEUROSCI.2385-13.2013

Copyright $\odot 2013$ the authors $\quad 0270-6474 / 13 / 3315333-10 \$ 15.00 / 0$
}

are well known to have distinct properties, including dendritic morphology, intrinsic physiology, and synaptic connectivity (Hattox and Nelson, 2007; Le Bé et al., 2007; Brown and Hestrin, 2009). In the mPFC, L2 pyramidal neurons also send long-range outputs, including to both the BLA and cmPFC (Gabbott et al., 2005; Hirai et al., 2012). These projection neurons thus appear well positioned to help govern the cognitive and emotional functions of the mPFC. However, much less is known about the cellular and synaptic properties of superficial pyramidal neurons compared with those found in deeper layers.

The mPFC also receives long-range excitatory inputs from an assortment of other brain regions (Hoover and Vertes, 2007). These inputs can arrive in layers that are not directly sampled by the dendrites of projection neurons, as in other agranular cortices (Mao et al., 2011; Hooks et al., 2013). To participate in reciprocal circuits, these inputs and neurons must first be linked by interlaminar connections (Weiler et al., 2008; Anderson et al., 2010). In contrast, excitatory inputs from the BLA and cmPFC densely arborize within superficial layers of the mPFC (Sesack et al., 1989; Bacon et al., 1996). These inputs are poised to directly synapse onto L2 pyramidal neurons whose dendrites sample from these layers (Little and Carter, 2012). This unique anatomy could enable bidirectional communication between these pyramidal neurons and the BLA and $\mathrm{cmPFC}$.

Here we examine reciprocal circuits linking L2 pyramidal neurons in the mPFC with both the BLA and cmPFC. We first define two non-overlapping populations of intermingled L2 pyramidal neurons that project to these brain regions. We then establish that neurons projecting to the BLA receive strong excitatory inputs from this same region. We show that this preferential connectivity is attributable to increased numbers of synapses tar- 
geting large spines in proximal dendrites. Together, our findings reveal a novel circuit that allows direct communication between the MPFC and BLA. Given the role of long-range interactions in cognitive and emotional control, our findings have important implications for both prefrontal function and disease.

\section{Materials and Methods}

Preparation. We studied L2 pyramidal neurons in acute slices from the prelimbic mPFC of P21 to P28 Swiss Webster mice of either sex. All procedures followed guidelines established by the New York University animal welfare committee. Mice were anesthetized with an intraperitoneal injection of a lethal dose of ketamine/xylazine. After anesthesia, mice were perfused intracardially with an ice-cold solution containing the following (in $\mathrm{mm}$ ): 65 sucrose, $75 \mathrm{NaCl}, 25 \mathrm{NaHCO}_{3}, 1.25 \mathrm{NaH}_{2} \mathrm{PO}_{4}, 25$ glucose, $2.5 \mathrm{KCl}, 1 \mathrm{CaCl}_{2}$, $5 \mathrm{MgCl}_{2}, 0.4 \mathrm{Na}$-ascorbate, and $2 \mathrm{Na}$-pyruvate (bubbled with $95 \% \mathrm{O}_{2} / 5 \%$ $\mathrm{CO}_{2}$ ). Coronal sections ( $300 \mu \mathrm{m}$ thick) were cut in this solution and transferred to artificial CSF (ACSF) containing the following (in mM): $119 \mathrm{NaCl}$, $25 \mathrm{NaHCO}_{3}, 1.4 \mathrm{NaH}_{2} \mathrm{PO}_{4}, 25$ glucose, $2.5 \mathrm{KCl}, 2 \mathrm{CaCl}_{2}, 1 \mathrm{MgCl}_{2}, 0.4 \mathrm{Na}$ ascorbate, and $2 \mathrm{Na}$-pyruvate (bubbled with $95 \% \mathrm{O}_{2} / 5 \% \mathrm{CO}_{2}$ ). Slices were recovered for $30 \mathrm{~min}$ at $34^{\circ} \mathrm{C}$ and then stored for at least $30 \mathrm{~min}$ at $24^{\circ} \mathrm{C}$. All experiments were conducted at $30-34^{\circ} \mathrm{C}$, except the two-photon mapping experiments, which were at $22-24^{\circ} \mathrm{C}$. For all experiments, $10 \mu \mathrm{M}$ gabazine and $10 \mu \mathrm{M}$ D-serine were included to block $\mathrm{GABA}_{\mathrm{A}}$ receptors and prevent NMDA receptor (NMDAR) desensitization, respectively. For most voltageclamp experiments, $1 \mu \mathrm{M}$ TTX and $0.1 \mathrm{~mm}$ 4-AP were included to block action potentials (APs) and restore presynaptic glutamate release, respectively. For paired-pulse stimulation experiments, these drugs were omitted to preserve physiological presynaptic APs. For strontium (Sr) experiments, 2 $\mathrm{mm} \mathrm{Ca}$ in the ACSF was replaced with $2 \mathrm{~mm} \mathrm{Sr}$ to evoke asynchronous release. In some experiments, $10 \mu \mathrm{M}$ NBQX or $10 \mu \mathrm{M} 3-((R)-2-$ carboxypiperazine-4-yl)-propyl-1-phosphonic acid (CPP) were added to block AMPA receptors (AMPARs) and NMDARs, respectively. All chemicals were from Sigma or Tocris Bioscience.

Stereotaxic injections. To target different neurons and inputs, we performed stereotaxic injections on P9-P12 mice, as described previously (Little and Carter, 2012). Injection site coordinates were relative to bregma (mediolateral axis, dorsoventral axis, and rostrocaudal axis: $\mathrm{cmPFC},+0.3$ $\mathrm{mm},-2.3$ to $-1.3 \mathrm{~mm}$, and $+1.7 \mathrm{~mm}$; BLA, $+2.8 \mathrm{~mm},-4.6 \mathrm{~mm}$, and -0.7 $\mathrm{mm})$. For anterograde tracing, we injected $100-200 \mathrm{nl}$ of virus [adenoassociated virus 2/9 (AAV2/9)-CAG-mCherry or AAV2/9-CAG-EGFP; University of Pennsylvania Vector Core]. For retrograde labeling, we injected a $0.2 \%$ dilution of Alexa Fluor-conjugated cholera toxin subunit B (CTB-Alexa 488 or CTB-Alexa 647; Invitrogen) or undiluted retrobeads (green or red; Lumafluor). For combined retrograde labeling and optogenetics, we injected a 1:1 mixture of 100-200 $\mathrm{nl}$ of virus (AAV2/9-CAGhChR2-mCherry; University of Pennsylvania Vector Core) and either red or green retrobeads. After injections, animals were returned to their cages for 2-3 weeks before being used for experiments.

Electrophysiology. We targeted L2 pyramidal neurons located in a dense band (approximately two to three neurons or $\sim 30 \mu \mathrm{m}$ thick) at the L1/L2 border, $\sim 200 \mu \mathrm{m}$ from the pial surface, using infrared-differential interference contrast. Corticoamygdalar (CA) and corticocortical (CC) neurons were identified based on the presence of red or green retrobeads. For voltageclamp experiments, borosilicate pipettes (2-5 M $\Omega$ ) were filled with the following (in mM): 135 Cs-gluconate, $10 \mathrm{HEPES}, 10 \mathrm{Na}$-phosphocreatine, 4 $\mathrm{Mg}_{2}$-ATP, 0.4 NaGTP, 0.6 D600, 10 TEA-Cl, 2 QX-314-Cl, and 10 EGTA, $\mathrm{pH} 7.35$ with $\mathrm{CsOH}$ (290-295 mOsm). For current-clamp recordings, we used the following (in mM): $135 \mathrm{~K}$-gluconate, $7 \mathrm{KCl}, 10 \mathrm{HEPES}, 10 \mathrm{Na}-$ phosphocreatine, $4 \mathrm{Mg}_{2}$-ATP, $0.4 \mathrm{NaGTP}$, and 0.5 EGTA, pH 7.35 with $\mathrm{KOH}$ (290-295 mOsm). For imaging experiments, $40 \mu \mathrm{M}$ Alexa Fluor 594 and $1 \mathrm{~mm}$ Fluo-4FF (Invitrogen) were included in the internal solution. We waited at least $15 \mathrm{~min}$ after patching before beginning mapping experiments, to allow for complete dye diffusion throughout the cell. Physiology data were collected with a Multiclamp 700B amplifier. Signals were filtered at $5 \mathrm{kHz}$ for current-clamp recordings and at $2 \mathrm{kHz}$ for voltage-clamp recordings and sampled at $10 \mathrm{kHz}$. Series resistance in voltage-clamp recordings was $<25$ $\mathrm{M} \Omega$ and not compensated.
Optogenetics. Glutamate release was triggered by activating channelrhodopsin-2 (ChR2) in the presynaptic terminals of different long-range excitatory inputs to the MPFC, as described previously (Little and Carter, 2012). In all optogenetic experiments, nearby CA and CC pairs were recorded in random order within the same slice. For wide-field illumination experiments, a single $0.5-8 \mathrm{~ms}$ pulse of $473 \mathrm{~nm}$ light from a light-emitting diode (LED) triggered release. When assessing responses in current clamp, data were only included when at least one neuron in the pair fired an AP in response to stimulation. For two-photon mapping and paired-pulse ratio (PPR) experiments, the back focal plane of the objective was filled with collimated light from a $473 \mathrm{~nm}$ laser (Laserglow Technologies) using a fiber-optic cable (Thorlabs), planoconvex lenses (Edmund Optics), and a dichroic mirror (Chroma Technologies), as described previously (Chalifoux and Carter, 2011). Beam diameter at the slice surface was $\sim 30 \mu \mathrm{m}$, allowing for focal ChR2 activation. Laser power was $\sim 4 \mathrm{~mW}$. For two-photon mapping experiments, a fast shutter (Uniblitz) was placed in the detection path to protect the photomultiplier tubes. Laser power and duration were chosen to elicit reliable EPSCs and limit photodamage. For PPR experiments, the laser beam was focused $\sim 200-300 \mu \mathrm{m}$ below the soma in L5 to prevent direct depolarization of presynaptic terminals in L1 and L2.

Two-photon microscopy. Two-photon imaging was performed on a custom microscope, as described previously (Chalifoux and Carter, 2010). Briefly, a titanium:sapphire laser (Coherent) tuned to $810 \mathrm{~nm}$ was used to excite Alexa Fluor 594 and Fluo-4FF to image morphology and detect Ca signals, respectively. Ca signals were quantified as the change in Fluo-4FF fluorescence [green (G)] normalized to the Alexa Fluor 594 fluorescence [red (R)], giving units of $\Delta G / R$. These signals were then normalized to the $G / R$ value measured with a saturating concentration of $\mathrm{Ca}$ added to the internal solution in a thin-walled pipette, giving final measurements in $\Delta \mathrm{G} / \mathrm{G}_{\mathrm{sat}}$. Imaging used a $63 \times, 1.0$ numerical aperture (NA) objective (Olympus).

Two-photon mapping. Active spines were mapped in the dendrites using a variant of a previously described technique (Little and Carter, 2012; MacAskill et al., 2012). As in other experiments, pairs of CA and CC neurons were sequentially patched in random order. After allowing dyes to equilibrate, a systematic search was performed to detect active spines in dendritic segments. Sampling began at dendrites terminating in either $\mathrm{L} 1$ or L2 and at segments either proximal or distal to the soma. For each segment, the $x, y$, and $z$ positions relative to soma were noted for offline analysis of spine locations. A high-resolution two-photon image stack $(0.1 \times 0.1 \times 0.2 \mu \mathrm{m})$ was also acquired for analysis of spine morphology. Identical numbers of segments were imaged at similar dendritic locations for both neurons in each pair to ensure unbiased sampling. The synapse density was computed as the number of detected spines in a neuron, divided by the number of sampled segments. At the end of each mapping experiment, a two-photon image stack of the cell was acquired $(1.0 \times$ $1.0 \times 1.0$ or $0.5 \times 0.5 \times 1.0 \mu \mathrm{m}$ ) for analysis of morphology.

Histology and confocal microscopy. Mice were anesthetized and perfused intracardially, as described above. Brains were blocked and transferred to $4 \%$ paraformaldehyde in $0.01 \mathrm{M} \mathrm{PBS}$ for $16-24 \mathrm{~h}$ at $4^{\circ} \mathrm{C}$ before being transferred to $0.01 \mathrm{M}$ PBS. Slices were cut on a VT-1000S vibratome (Leica) at $50 \mu \mathrm{m}$ thickness and placed on gel-coated glass slides. ProLong Gold antifade reagent with DAPI (Invitrogen) was applied with $0.01 \mathrm{M}$ PBS to the surface of the slices, which were then covered with a glass coverslip. All confocal images were taken on a Leica TCX SP5. Images of anterograde anatomy and retrograde anatomy used for CA and CC localization were taken with a $40 \times, 1.5 \mathrm{NA}$ oil-immersion objective at $1024 \times 1024$ pixels $(0.34 \times 0.34 \mu \mathrm{m})$. To ensure that channel bleedthrough did not influence our colocalization analysis, fluorophores were chosen with widely separated excitation and emission spectra and were sequentially acquired as dual-fluorescence images.

Simulations. To predict the probability that CA and CC neurons generate APs in response to BLA input, we modified a previously described model of L2 pyramidal neurons (Little and Carter, 2012). We first sampled the volumes and locations of spines contacted by BLA inputs at CA and CC neurons. We then predicted the size of the somatic unitary EPSP (uEPSP) at each of these spines, based on two-photon uncaging experiments (Little and Carter, 2012). We linearly summed individual uEPSPs 
A

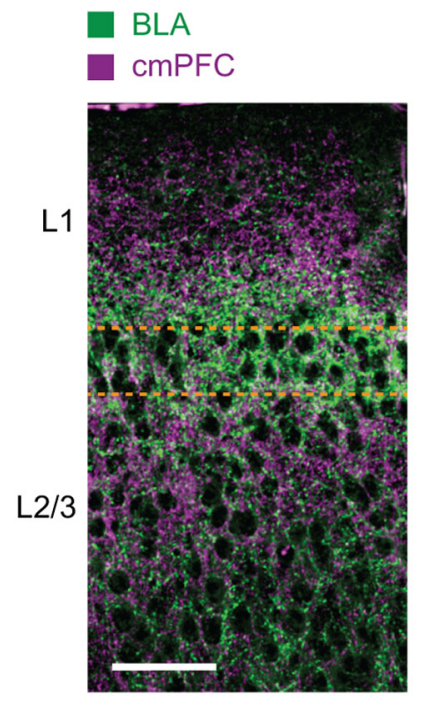

B

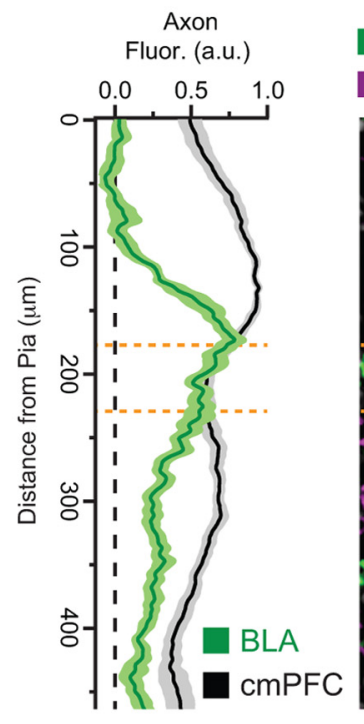

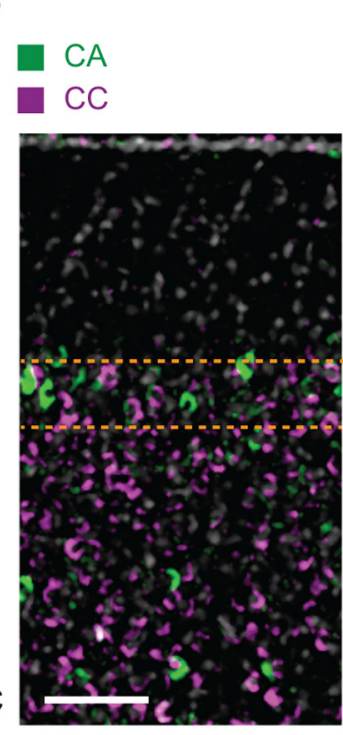

C

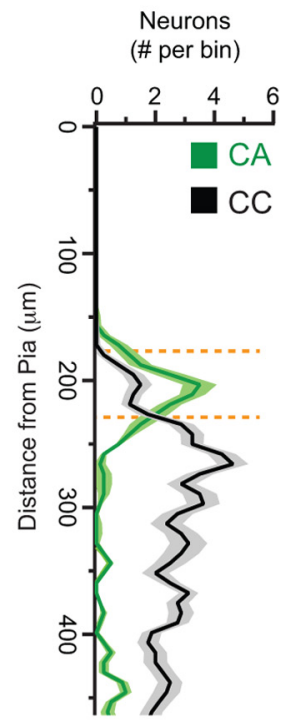

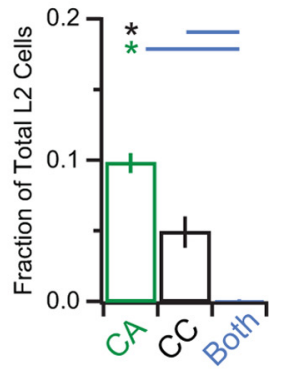

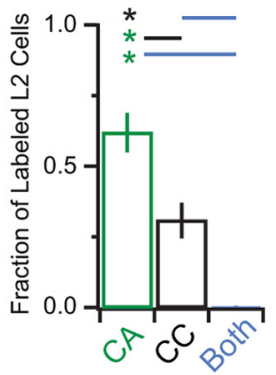

Figure 1. Anatomical basis of reciprocal circuits in the mPFC. A, Left, Anterogradely labeled axons from the BLA (green) and cmPFC (magenta) in the mPFC. Scale bar, $100 \mu \mathrm{m}$. Right, Normalized BLA (green) and cmPFC (black) axon fluorescence as a function of distance from the pial surface. Orange dotted lines show the approximate region of L2 considered in this study. $\boldsymbol{B}$, Left, Retrogradely labeled CA (green) and CC (magenta) L2 pyramidal neurons in the mPFC. Gray shows DAPI-positive nuclei. Scale bar, $100 \mu \mathrm{m}$. Right, Median number of CA (green) and CC (black) neurons as a function of distance from the pial surface. C, Summary of the number of CA neurons, CC neurons, and dual-projecting neurons as a fraction of total cells in L2 (top) or labeled cells in L2 (bottom). Asterisks indicate significant comparisons. Color of asterisks and lines indicate which groups are compared.

to reach an experimentally determined threshold of $-48 \mathrm{mV}$. For each neuron, we simulated 1-100 synapses and computed the spike probability over 1000 runs. To independently assess the impact of spine volume or dendritic location, we also generated predictions in which (1) the CA distribution of spine volume was replaced by the CC distribution or (2) the CA distribution of dendritic location was replaced by the CC distribution. To simulate the effect of the synapse density of BLA inputs, we also ran simulations in which CC neurons received an experimentally determined $50 \%$ fewer inputs. Spike probability curves were plotted as a function of the fraction of total number of BLA inputs rather than the absolute numbers because the latter are unknown.

Data analyses. Imaging and physiology data were acquired using National Instruments boards and custom software written in MATLAB (MathWorks). Online spine Ca signal detection was performed in MATLAB. Image preprocessing was performed in NIH ImageJ and MATLAB. Morphological analysis was conducted in NeuronStudio (Dumitriu et al., 2011). Ca imaging and physiology analysis was performed in Igor Pro (Wavemetrics). In current-clamp experiments, output gain was quantified as the slope of the frequency/current $(F / I)$ curve. In Sr experiments, quantal EPSCs (qEPSCs) were detected in $600 \mathrm{~ms}$ windows after the stimulus, using threshold-based, event-detection functions in NeuroMatic, with the threshold set at 4 standard deviations (SDs) above noise. Spontaneous EPSCs (sEPSCs) were detected in a $600 \mathrm{~ms}$ window before the stimulus.

For analysis of two-photon image stacks, all visible dendrites of each mapped neuron were reconstructed in NeuronStudio, as described previously (Little and Carter, 2012). To quantify the distributions of axons from our confocal images and determine the colocalization of CA and CC neurons, background subtraction was performed on each slice, followed by manual alignment. For axon analysis, intensity profiles were averaged across multiple slices (for each input, $n=3$ animals, 7 slices), as described previously (Little and Carter, 2012). For colocalization, dualfluorescent pixels were detected and overlaid on a dual-color image of retrogradely labeled CA and CC neurons. Somata with colocalized pixels, as well as large DAPI-positive nuclei, were manually counted in regions $40 \times 100 \mu \mathrm{m}$ centered on L2 of mPFC.

EPSC and qEPSC amplitudes were calculated as the average value over a $1 \mathrm{~ms}$ window around the peak. Standard errors (SEs) were calculated via bootstrap resampling (10,000 surrogates). For experiments with se- quential recordings, summary comparisons are expressed as both medians \pm SE of raw data and medians \pm SE of the ratios of these data. Some data are presented in box-plot form, showing the median, interquartile range, and 10-90\% range (whiskers). Average EPSCs, qEPSCs, and EPSPs are shown in figures as individual trials or arithmetic mean \pm SE. Statistical comparisons were performed using the two-tailed MannWhitney rank-sum test, except in Figure 6, in which a bootstrap permutation test on data medians was used. Correlations are reported as the linear correlation coefficient $(r)$, and significance of correlations was tested with a linear correlation test.

\section{Results}

\section{Distinct populations of L2 projection neurons}

We examined how pyramidal neurons in superficial layers of the prelimbic mPFC communicate with the BLA and cmPFC. We first used anterograde labeling to establish where inputs from these two brain regions are distributed in the mPFC. We injected AAV-EGFP into the BLA and AAV-mCherry into the cmPFC and examined the profiles of fluorescently labeled axons. We found that BLA axons arborized in a narrow band at the border of L1 and L2, whereas cmPFC axons were more distributed throughout the superficial layers (Fig. 1A). These stereotyped profiles suggest that BLA and $\mathrm{cmPFC}$ inputs could make unique synaptic connections onto the dendrites of L2 pyramidal neurons in the mPFC.

We next used retrograde labeling to identify which populations of pyramidal neurons project to the BLA and cmPFC. We coinjected fluorescently tagged CTB into the BLA (CTB-Alexa 488) and cmPFC (CTB-Alexa 647) and detected fluorescently labeled corticoamygdalar (CA) and corticocortical (CC) neurons in the mPFC. CA neurons were concentrated near the L1/L2 border, whereas CC neurons were distributed throughout the superficial layers (Fig. 1B). Labeled neurons were a minority of the total L2 population $(\mathrm{CA}=9.8 \pm 0.7 \%$; $\mathrm{CC}=4.9 \pm 1.1 \% ; n=3$ animals; Fig. $1 C$ ). However, CA neurons constituted the majority 
of labeled neurons $(\mathrm{CA}=62 \pm 7 \%$; $\mathrm{CC}=$ $31 \pm 6 \%)$, and these two cell types did not overlap $(0.0 \pm 0.1 \%)$. These results indicate that CA and CC neurons are two distinct populations of pyramidal neurons in the superficial layers of the $\mathrm{mPFC}$.

\section{Morphology and physiology of CA and CC neurons}

In deeper layers of the mPFC, different populations of L5 pyramidal neurons have unique dendritic arborizations (Morishima and Kawaguchi, 2006; Dembrow et al., 2010; Morishima et al., 2011; Otsuka and Kawaguchi, 2011). We next sought to establish whether CA and CC neurons also had distinct morphological properties. For these experiments, we injected green retrobeads into the BLA and red retrobeads into the cmPFC, which are taken up by axons and retrogradely transported to the mPFC (Hattox and Nelson, 2007). We then used whole-cell recordings to selectively record from labeled L2 pyramidal neurons (Fig. 2A). We filled CA and CC neurons with fluorescent dyes and used two-photon microscopy to characterize their dendritic arbors (Little and Carter, 2012). We found that the morphology of these neurons was largely similar, as assessed by their total dendritic lengths $(\mathrm{CA}=2.8 \pm 0.2 \mathrm{~mm}, n=19$ cells; $\mathrm{CC}=3.1 \pm 0.3 \mathrm{~mm}, n=17$ cells; $p=$ 0.79 ; Fig. $2 B$ ). There were only subtle morphological differences, with CC neurons having more dendrites at distal locations (Fig. 2C). These findings suggest that the dendrites of these two neurons may sample excitatory inputs arriving in the superficial layers from the BLA and cmPFC.

Depending on their targets, different populations of deeplayer pyramidal neurons also exhibit a range of firing properties (Morishima and Kawaguchi, 2006; Dembrow et al., 2010; Morishima et al., 2011; Otsuka and Kawaguchi, 2011). We next used current-clamp recordings to characterize the physiological properties of CA and CC neurons. Current steps evoked repetitive APs in both populations (Fig. 2D) and more firing with increasing current (Fig. 2E). Over many recordings, we found that these neurons had indistinguishable resting potentials $(\mathrm{CA}=$ $-77.7 \pm 2.8 \mathrm{mV}, n=9$ cells; $\mathrm{CC}=-80.5 \pm 4.3 \mathrm{mV}, n=7$ cells; $p=0.72$; Fig. $2 F)$, input resistances $(\mathrm{CA}=176 \pm 16 \mathrm{M} \Omega$; $\mathrm{CC}=$ $197 \pm 30 \mathrm{M} \Omega ; p=0.44$; Fig. $2 G)$, threshold potentials $(\mathrm{CA}=$ $-48.3 \pm 2.0 \mathrm{mV} ; \mathrm{CC}=-47.9 \pm 3.4 \mathrm{mV} ; p=0.46$; Fig. $2 \mathrm{H})$, and output gains $(\mathrm{CA}=2.6 \pm 0.34 ; \mathrm{CC}=2.4 \pm 0.32 ; p=0.86$; Fig. $2 I)$. These results indicate that CA and CC neurons have equivalent physiological properties and may similarly transform synaptic inputs into APs.

\section{Cell- and input-specific synaptic connectivity}

Although their anatomical and physiological properties appear similar, CA and CC neurons may participate in distinct circuits. We next used a combination of optogenetics and targeted recordgain $(I)$ of $C A$ and $C($ neurons.
B

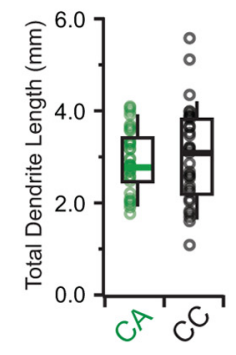

C

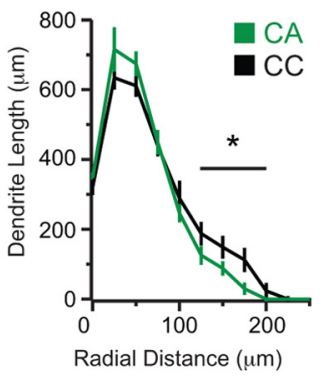

E
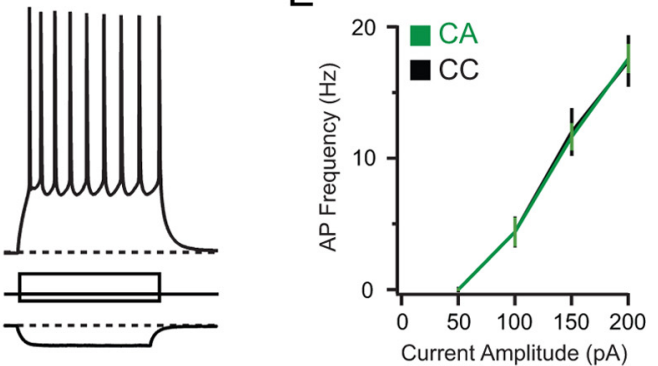

I

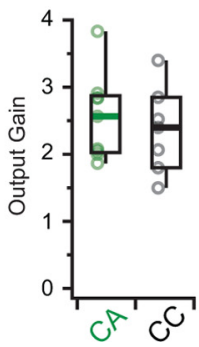

Figure 2. $C A$ and $C C$ neuron morphology and physiology. A, Sequential whole-cell recordings of nearby CA (green) and CC Ore approximate region of $\mathrm{L} 2$ considered in this study. Scale bar, $10 \mu \mathrm{m}$. $\boldsymbol{B}$, Total dendrite length of in $C A$ and $C($ neurons. $\boldsymbol{E}$, Resulting $F / /$ curves. $\boldsymbol{F}-\boldsymbol{I}$, Resting potential $(\boldsymbol{F})$, input resistance $(\boldsymbol{G})$, threshold potential $(\boldsymbol{H})$, and output

ings to assess whether BLA and mPFC inputs make selective contacts onto these two types of pyramidal neurons. To selectively activate inputs from the BLA and cmPFC, we injected AAVChR2 into one of these two regions. To identify projection cells, we also injected green retrobeads into the BLA and red retrobeads into the cmPFC of the same animals. After allowing for viral expression and bead transport, we then made sequential wholecell recordings from pairs of nearby CA and CC neurons while stimulating excitatory inputs with a wide-field LED (Fig. 3A). These experiments were performed in the presence of TTX (1 $\mu \mathrm{M})$ to block polysynaptic activity and 4 -AP $(0.1 \mathrm{mM})$ to restore glutamate release (Petreanu et al., 2009; Cruikshank et al., 2010; Little and Carter, 2012). These targeted recordings of nearby CA and CC neurons enabled paired comparisons of synaptic strength for different inputs and minimized response variability caused by infection efficiency or slice orientation.

In voltage-clamp recordings at $-70 \mathrm{mV}$, with $\mathrm{CPP}(10 \mu \mathrm{M})$ to block NMDARs and gabazine $(10 \mu \mathrm{M})$ to block GABA $\mathrm{As}$, we found that both BLA and cmPFC inputs generated AMPAR EPSCs at neighboring CA and CC neurons. However, BLA inputs evoked larger responses at CA neurons ( $8 \mathrm{~ms}$ pulse: $\mathrm{CA}=88 \pm 20$ $\mathrm{pA} ; \mathrm{CC}=31 \pm 18 \mathrm{pA} ; n=10$ pairs; $p=0.007$; Fig. $3 A)$. In 
A

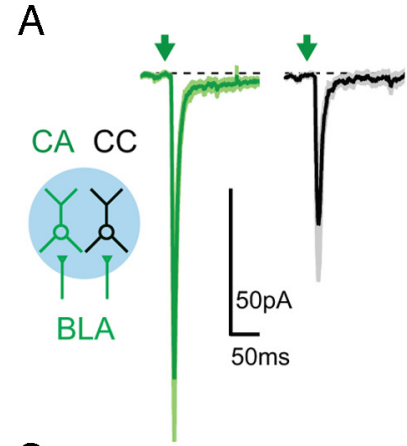

C

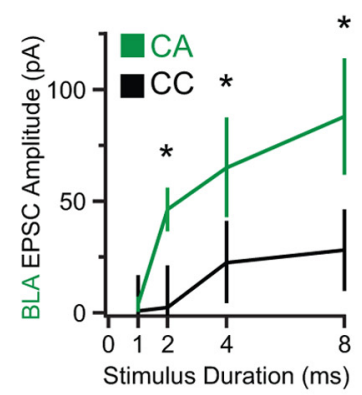

$E$

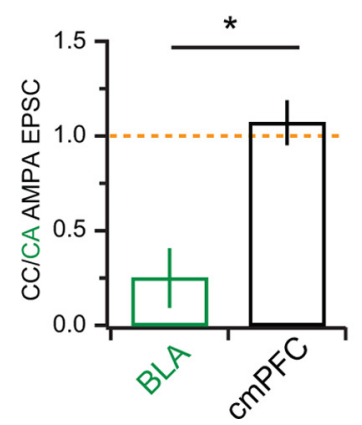

B

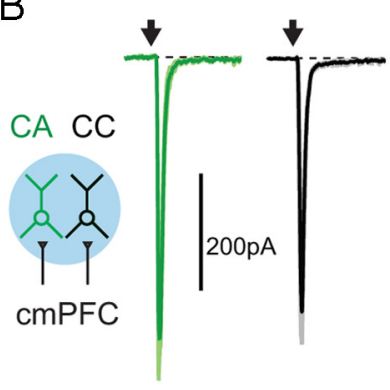

D

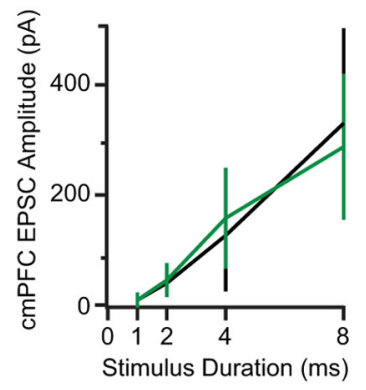

$\mathrm{F}$

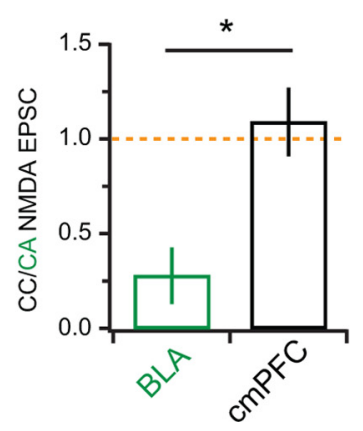

Figure 3. Synaptic strength of BLA and cmPFC inputs. $A$, Left, Schematic showing activation of BLA inputs (green) onto CA (green) and CC (black) neurons via wide-field illumination (blue). Right, AMPAR EPSCs evoked by BLA inputs at sequentially recorded CA and CC neurons. Arrows denote LED stimulation. $\boldsymbol{B}$, Same as $\boldsymbol{A}$ but for $\mathrm{cmPFC}$ inputs. $\boldsymbol{C}$, Summary of AMPAR EPSC amplitudes as a function of pulse duration for BLA inputs. D, Same as in Cbut for cmPFC inputs. E, Ratio of AMPAR EPSCs at CC and CA neurons evoked by BLA (green) or cmPFC (black) inputs. $\boldsymbol{F}$, Same as in $\boldsymbol{E}$ but for NMDAR EPSCs. Asterisks indicate significance. Orange dotted line indicates a CC/CA ratio of unity.

contrast, cmPFC inputs evoked equivalent responses at the two cell types $(\mathrm{CA}=280 \pm 133 \mathrm{pA} ; \mathrm{CC}=288 \pm 172 \mathrm{pA} ; n=8$ pairs; $p=0.25$; Fig. $3 B$ ). Similar results were observed using a range of light durations, which recruit varying numbers of presynaptic inputs (Fig. 3C,D). On average, BLA inputs generated larger AMPAR EPSCs at CA neurons, whereas cmPFC evoked very similar responses at the two cell types (CC/CA ratio: $\mathrm{BLA}=0.25 \pm 0.17$; $\mathrm{cmPFC}=1.07 \pm 0.12 ; p=0.012$; Fig. $3 E)$. We also observed equivalent targeting with NMDAR EPSCs recorded at $+40 \mathrm{mV}$ in the presence of NBQX $(10 \mu \mathrm{M})$ to block AMPARs (CC/CA ratio: $\mathrm{BLA}=0.28 \pm 0.15, n=6$ pairs; $\mathrm{cmPFC}=1.09 \pm 0.18, n=9$ pairs; $p=0.036$; Fig. $3 F$ ). These results indicate that the $\mathrm{mPFC}$ participates in direct reciprocal circuits with both the BLA and cmPFC. Moreover, the mPFC establishes a preferentially strong reciprocal circuit with the BLA, because inputs from the BLA show biased synaptic strength onto their associated projection neurons.

A
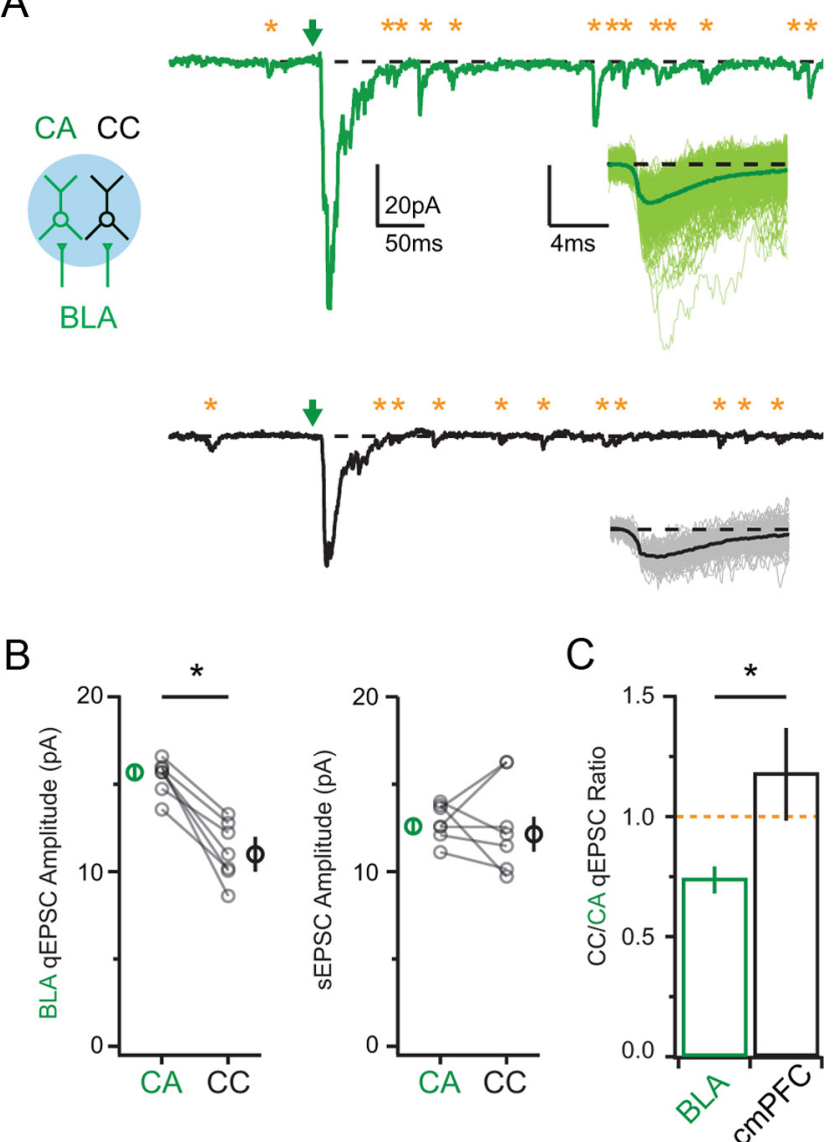

Figure 4. Postsynaptic properties of BLA inputs. $A$, Left, Schematic showing activation of BLA inputs (green) onto CA (green) and CC (black) neurons via wide-field illumination. Right, AMPAR synaptic responses evoked in the presence of $2 \mathrm{~mm}$ Sr. Arrows indicate LED onset. Asterisks denote detected qEPSCs (right of arrow) and sEPSCs (left of arrow). Insets, Overlay of individual (thin) and average (thick), onset-aligned qEPSCs evoked by BLA inputs. $\boldsymbol{B}$, Left, Summary of qEPSCs evoked by BLA inputs at CA and CC neurons. Right, Summary of sEPSCs in the same recordings. $C$, Ratio of qEPSCs at C $C$ and CA neurons evoked by BLA (green) and cmPFC (black) inputs. Asterisks indicate significance. Orange dotted line indicates a CC/CA ratio of unity.

\section{Different postsynaptic properties of BLA inputs}

In principle, a variety of presynaptic and postsynaptic parameters could contribute to the differential strength of BLA inputs at CA and CC neurons (Gil et al., 1999). One possibility is that the amplitude of quantal responses to BLA inputs differs at these L2 pyramidal neurons. To test this, we substituted extracellular calcium for $\mathrm{Sr}(2 \mathrm{~mm})$, which enhances asynchronous release and reveals input-specific quantal EPSCs (qEPSCs) (Goda and Stevens, 1994; Hull et al., 2009; MacAskill et al., 2012). Under these conditions, wide-field illumination of BLA inputs generated qEPSCs at both CA and CC neurons (Fig. 4A). However, these responses were significantly larger at $\mathrm{CA}$ neurons $(\mathrm{CA}=15.7 \pm$ $0.4 \mathrm{pA} ; \mathrm{CC}=11.0 \pm 1.0 \mathrm{pA} ; \mathrm{CC} / \mathrm{CA}$ ratio $=0.75 \pm 0.06 ; n=7$ pairs; $p=0.016$; Fig. $4 B, C)$. Moreover, qEPSCs evoked by BLA inputs were significantly larger than spontaneous EPSCs (sEPSCs) before the light pulse at CA neurons $(12.6 \pm 0.6 \mathrm{pA} ; p=$ $0.015)$ but not CC neurons ( $12.2 \pm 1.6 \mathrm{pA} ; p=0.58$; Fig. $4 B)$. In contrast, qEPSCs evoked by cmPFC inputs were similar between the two cell types $(\mathrm{CA}=10.3 \pm 0.4 \mathrm{pA} ; \mathrm{CC}=10.7 \pm 1.9 \mathrm{pA}$; $\mathrm{CC} / \mathrm{CA}$ ratio $=1.2 \pm 0.2 ; n=6$ pairs; $p=0.55$; Fig. $4 C)$. These results indicate that the individual connections formed by BLA inputs onto CA neurons have enhanced synaptic strength relative 
A

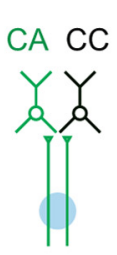

BLA

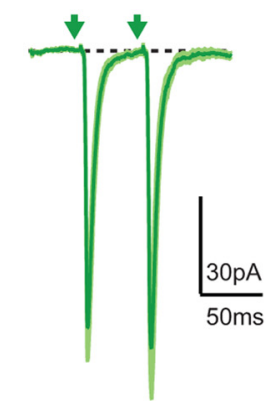

B

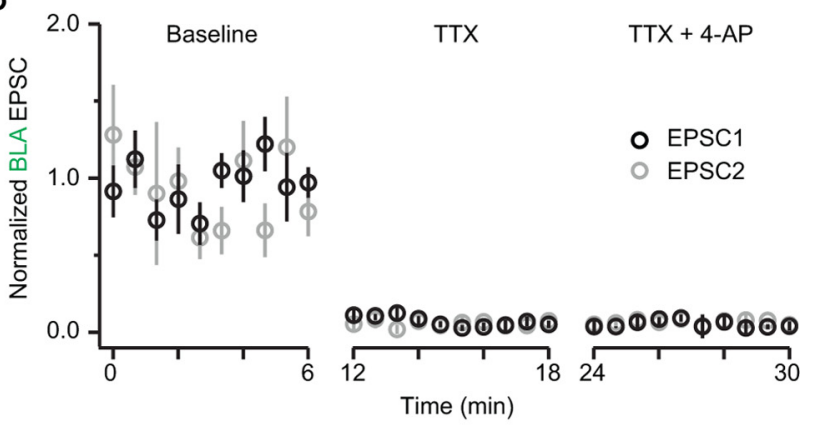

C

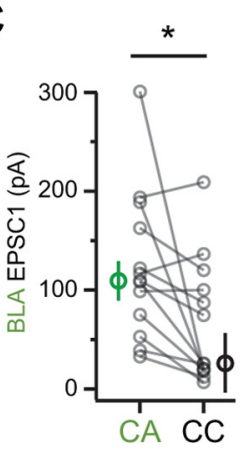

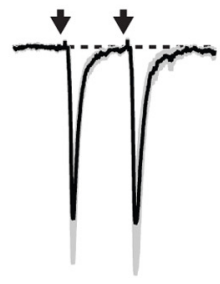

D

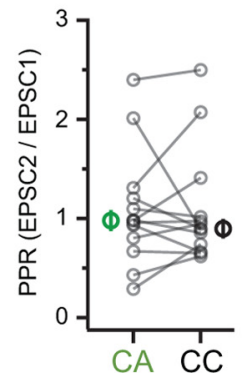

Figure 5. Presynaptic properties of BLA inputs. $A$, Left, Schematic showing activation of distant BLA axons (green) onto CA (green) and CC (black) neurons using focused illumination with a blue laser. Right, AMPAR EPSCs evoked by paired-pulse stimulation of BLA inputs (interstimulus interval, $50 \mathrm{~ms}$ ). $\boldsymbol{B}$, Summary time course of normalized EPSC amplitudes during baseline (left), bath application of TTX (middle), and subsequent bath application of 4-AP (right). C, Summary of median (thick circles) and individual (thin circles) amplitudes for EPSC1 (left) and EPSC2 (right) at CA (green) and CC (black) neurons. D, Summary of PPR at CA (green) and CC (black) neurons. Asterisks indicate significance.

to CC neurons. However, although these responses were larger in CA neurons, the CC/CA ratios for qEPSCs were smaller than for compound EPSCs, suggesting that other factors also contribute to differences in overall synaptic strength.

\section{Similar presynaptic properties of BLA inputs}

Another possibility is that presynaptic factors, including the probability of release, could differ at BLA inputs onto the two projection cells. We next examined the paired-pulse ratio (PPR) of BLA synapses onto CA and CC neurons, which gives an indication of release probability. For these experiments, we activated BLA inputs with a $473 \mathrm{~nm}$ laser spot $(\sim 30 \mu \mathrm{m}$ diameter $)$ positioned within L5 ( $\sim 200-300 \mu \mathrm{m}$ from L2) (Petreanu et al., 2007). This focal stimulation avoided direct stimulation of presynaptic terminals, which could otherwise disrupt physiological glutamate release (Zhang and Oertner, 2007). In voltage-clamp recordings at $-70 \mathrm{mV}$, we found that paired-pulse stimulation of BLA inputs (interstimulus interval, $50 \mathrm{~ms}$ ) evoked AMPAR EPSCs at both CA and CC neurons (Fig. 5A). These responses were

blocked by TTX $(1 \mu \mathrm{M})$ and not rescued by subsequent $4-\mathrm{AP}(0.1$ $\mathrm{mM})$, confirming that they depend on presynaptic activity $(n=6$ neurons; Fig. 5B). Consistent with our initial experiments, the first and second EPSCs were larger at CA neurons (EPSC1: CA = $109.4 \pm 20.0 \mathrm{pA} ; \mathrm{CC}=26.0 \pm 30.6 \mathrm{pA} ; \mathrm{EPSC} 2 \mathrm{CA}=92.4 \pm 33.1$ pA; $\mathrm{CC}=24.6 \pm 22.0$ pA; $n=13$ pairs; Fig. $5 C$ ). However, PPR was similar at CA and CC neurons (EPSC2/EPSC1 ratio: CA = $0.98 \pm 0.11 ; \mathrm{CC}=0.90 \pm 0.10 ; p=0.74$; Fig. 5D). Accordingly, there was a high correlation between PPR at CA and CC neurons within each pair $(r=0.69 ; p=0.01)$. These results indicate that the release probability of BLA inputs is similar at these neurons, suggesting that presynaptic factors do not play a major role in producing differences in synaptic strength at these two cell types.

\section{Subcellular synaptic connectivity of BLA inputs}

The presynaptic and postsynaptic properties we examined cannot fully explain the large differences in synaptic strength of BLA inputs onto CA and CC neurons. One additional possibility is that BLA inputs also form different numbers of connections onto these two cell types. We next used two-photon microscopy to directly map functional connections at the level of individual spines (Little and Carter, 2012; MacAskill et al., 2012). For these experiments, we sequentially patched neighboring CA and CC neurons and filled them with both a morphological indicator (Alexa Fluor 594) and Ca indicator (Fluo-4FF). We then focused a laser over dendritic segments to activate ChR2 and trigger presynaptic release from BLA inputs. In voltage-clamp recordings at $+10 \mathrm{mV}$, we imaged evoked NMDAR Ca signals to detect spines responding to glutamate release. This approach allowed us to detect functional BLA synapses onto spines located throughout the dendritic arbor of both populations of projection cells.

We first assessed the density of BLA connections onto equivalent dendritic segments in neighboring CA and CC neurons (Fig. 6A). We restricted our two-photon mapping to segments within $150 \mu \mathrm{m}$ of the L1 border, in which our anatomy indicated that BLA axons are concentrated. We defined synapse density as the number of active spines divided by the number of sampled dendritic segments, with equal sampling of segments across each pair. By mapping multiple segments in each neuron, we determined that synapse density was greater at CA neurons $(\mathrm{CA}=$ $0.25 \pm 0.04, n=43$ spines; $\mathrm{CC}=0.17 \pm 0.04, n=26$ spines; $\mathrm{CC} / \mathrm{CA}$ ratio $=0.50 \pm 0.06, n=21$ pairs; $p=0.004$; Fig. $6 B$ ). These findings indicate that BLA inputs are twice as likely to form connections onto CA neurons.

Additional analysis of our mapping experiments revealed two additional ways in which the subcellular connections made by BLA inputs differ between these neurons. First, we found that the head volumes of BLA-contacted spines were larger at CA neurons $\left(\mathrm{CA}=0.68 \pm 0.13 \mu \mathrm{m}^{3} ; \mathrm{CC}=0.41 \pm 0.13 \mu \mathrm{m}^{3} ; p=0.0052\right.$; Fig. $6 C)$. Spines contacted by BLA inputs were also larger than adjacent spines at CA neurons $\left(0.41 \pm 0.08 \mu \mathrm{m}^{3} ; p=0.006\right)$ but not CC neurons $\left(0.44 \pm 0.05 \mu \mathrm{m}^{3} ; p=0.16\right)$. These findings are consistent with the results from our Sr experiments and indicate that BLA inputs preferentially contact larger spines on CA neurons but innervate spines on CC neurons more randomly.

Surprisingly, we found that BLA inputs were also more likely to synapse on spines at more proximal locations on CA neurons $(\mathrm{CA}=44.3 \pm 6.3 \mu \mathrm{m} ; \mathrm{CC}=66.9 \pm 11.4 \mu \mathrm{m} ; p=0.028$; Fig. $6 D)$. Importantly, the sampling distances in these mapping experiments were equivalent at both cell types $(\mathrm{CA}=47.3 \pm 3.0 \mu \mathrm{m}$; $\mathrm{CC}=46.2 \pm 3.4 \mu \mathrm{m} ; p=0.96)$. This dendritic targeting was also observed when plotting median spine probability as a function of vertical displacement toward the pial surface (Fig. 6E) or hori- 
A
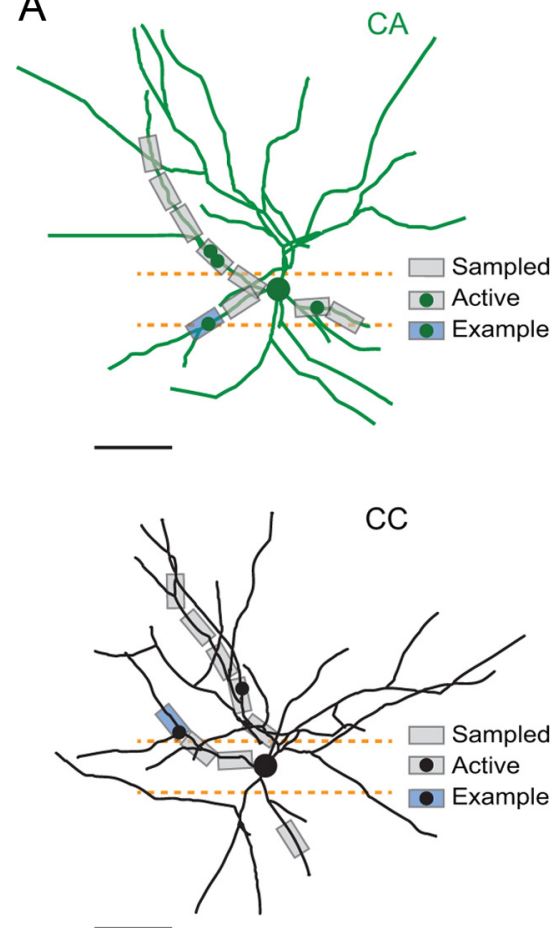

B
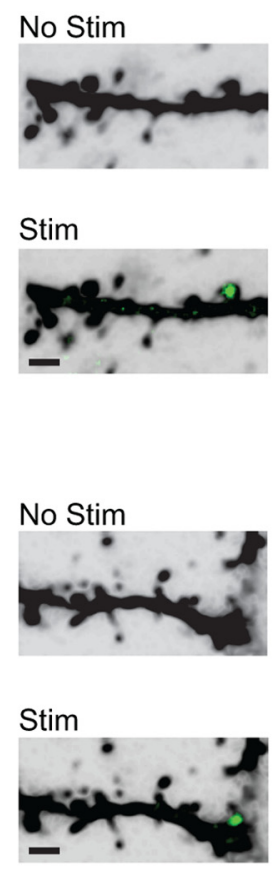

$E$
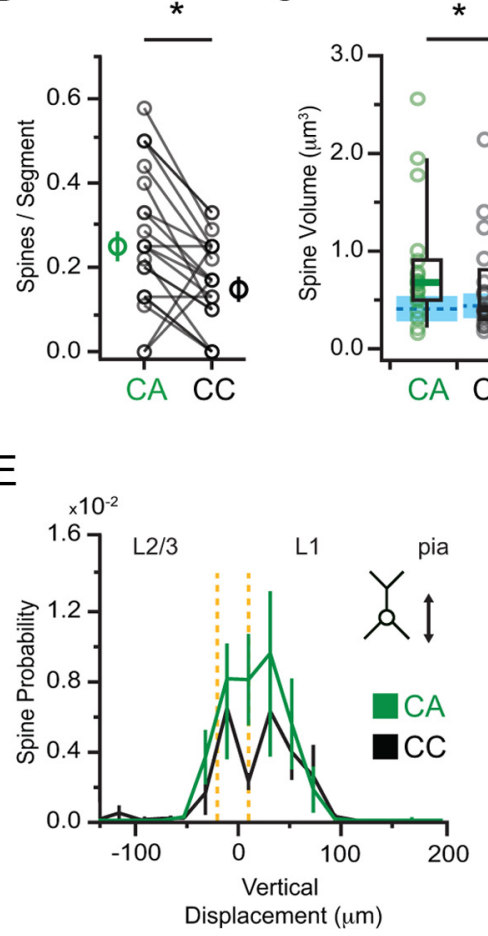

C

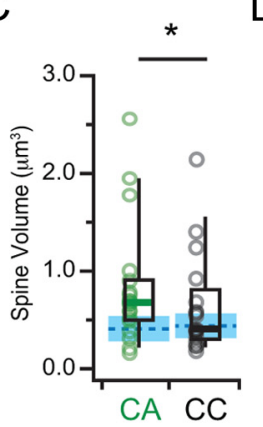

D

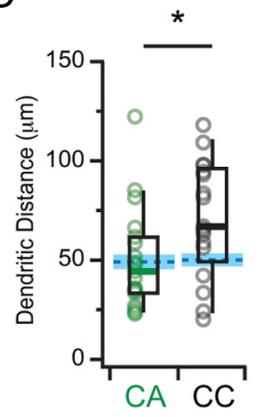

Figure 6. Synapse density and subcellular targeting of BLA inputs. $A$, Left, Example of two-photon mapping of BLA inputs onto a reconstructed CA neuron (top) and neighboring CC neuron (bottom). Gray boxes indicate sampled dendritic segments. Dots indicate positions of identified spines. Blue boxes indicate example segments. Scale bars, $100 \mu \mathrm{m}$. Right, Example dendritic segments before and after stimulation of BLA inputs. Black indicates morphology of spines and dendrites. Green indicates ChR2-evoked Ca signals. B, Summary of median (thick circles) and individual (thin circles) density of spines contacted by BLA inputs at CA (green) and CC (black) neurons. C, Summary of volumes of contacted spines. Blue lines indicate median and SE of volumes of non-active spines at the two cell types. $\boldsymbol{D}$, Summary of distance from the soma along the dendrite of contacted spines at the two cell types. Blue lines indicate median and $\mathbf{E}$ of the sampling distances. $\boldsymbol{E}$, Median probability of finding contacted spines as a function of vertical $(y)$ displacement from the soma toward the pial surface. $\boldsymbol{F}$, Same as in $\boldsymbol{E}$ but for horizontal $(x)$ displacement from the soma along the L1/L2 border. Asterisks indicate significance. Orange dotted lines show the approximate region of L2 considered in this study.

zontal displacement along the L1/L2 border (Fig. $6 F$ ). These findings indicate that BLA inputs target spines near the soma of CA neurons. Together, these two-photon mapping experiments reveal how synapse density and subcellular targeting differ at the two cell types.

\section{Impact of synaptic connectivity on functional output}

Our findings revealed synaptic mechanisms that could allow BLA inputs to be stronger at CA neurons than nearby CC neurons. We next determined the relative contributions of these mechanisms to differences in overall synaptic drive at these two populations. We used a linear model of EPSP summation to assess the effects of spine volume, dendritic location, and synapse density on AP firing. We first simulated the effects of subcellular targeting independent of any differences in synapse density (Fig. 7A). We ran the model while sampling the distributions of spine volume and dendritic location measured from CA and CC neurons. We found that fewer BLA inputs were needed to fire CA neurons ( $53 \pm 0.8 \%$ of total; $n=20$ simulations) than CC neurons ( $68 \pm$ $\left.0.4 \% ; p=2 \times 10^{-6}\right)$. Intermediate values were found when independently swapping either spine volume $(61 \pm 0.4 \%$; $p=$ $\left.2 \times 10^{-6}\right)$ or dendritic location $\left(58 \pm 0.5 \% ; p=2 \times 10^{-6}\right)$ between CC and CA neurons, indicating that both of these parameters contribute to the ability to fire these neurons. Finally, to assess the impact of the synapse density, we scaled the total number of BLA inputs onto CC neurons by $50 \%$, consistent with our mapping experiments (Fig. $7 B$ ). We found that reducing synapse density in this way effectively prevented CC neurons from responding by firing APs. Together, these simulations predict that subcellular connectivity enables BLA inputs to form preferentially strong synapses at CA neurons.

To validate these modeling predictions, we next performed current-clamp recordings with wide-field stimulation of excitatory inputs. These experiments were performed in the absence of TTX and 4-AP, which would otherwise perturb synaptic responses and AP firing. To avoid complications from polysynaptic activity, we also restricted our analysis to a short time window after the stimulus pulse $(20 \mathrm{~ms})$. We found that BLA inputs reliably triggered APs from resting potentials at CA neurons $(8 \mathrm{~ms}$ pulse: spike probability $=0.7 \pm 0.20 ; n=7$ pairs) but not nearby CC neurons $(0.0 \pm 0.20 ; p=0.031$; Fig. $7 C)$. In contrast, $\mathrm{cmPFC}$ inputs reliably triggered APs in both cell types with equal likelihood $(\mathrm{CA}=1.0 \pm 0.19 ; \mathrm{CC}=1.0 \pm 0.14 ; p=0.5 ;$ Fig. $7 D)$. Overall, BLA inputs exhibit a strong bias in driving CA neurons $(\mathrm{CC} / \mathrm{CA}$ ratio $=0.0 \pm 0.16)$, which was not found for $\mathrm{cmPFC}$ inputs $(\mathrm{CC} / \mathrm{CA}$ ratio $=1.0 \pm 0.09$; Fig. $7 E)$. These results highlight the importance of differences in synaptic strength and show that BLA inputs can preferentially drive feedback interactions in the $\mathrm{mPFC}$.

\section{Discussion}

We examined reciprocal circuits that connect the $\mathrm{MPFC}$ and two of its key target brain regions. We first identified distinct L2 pyramidal neurons that project to either the BLA (CA neurons) or cmPFC (CC neurons). We then showed that these neurons receive direct excitatory inputs from their own projection targets. Inputs from the BLA are much stronger onto CA neurons than neighboring CC neurons, indicating preferential synaptic con- 
nectivity. Using two-photon mapping, we demonstrated that synapse density, spine volume, and dendritic location all differ at CA and CC neurons. These properties combine to enable BLA inputs to drive AP output most effectively in CA neurons. These results highlight the synaptic organization of a direct reciprocal circuit between the MPFC and BLA.

\section{Reciprocal circuits involving L2 pyramidal neurons}

In many cortical areas, functional interactions with other brain regions are organized through polysynaptic circuits. In granular cortex, long-range excitatory inputs often arrive in L4, whereas equivalent outputs arise from deeper layers (Douglas and Martin, 2004). However, the mPFC is agranular and lacks a defined L4, meaning that this canonical circuit does not apply. Instead, both deep and superficial layers receive long-range inputs from cortical and subcortical regions (Sesack et al., 1989; McDonald, 1991; Hoover and Vertes, 2007). Pyramidal neurons in different layers also send long-range outputs to a variety of targets (McDonald et al., 1996; Gabbott et al., 2005). Local processing of different inputs undoubtedly occurs within and between individual cortical layers (Kampa et al., 2006; Le Bé et al., 2007; Weiler et al., 2008; Brown and Hestrin, 2009; Anderson et al., 2010; Hooks et al., 2011; Kiritani et al., 2012). However, our anatomy suggested that superficial neurons participate in direct reciprocal circuits with $\mathrm{cmPFC}$ and BLA. These neurons are thus uniquely positioned to directly link these distant regions without additional interlaminar signaling.

Many studies have highlighted the diversity of pyramidal neurons in deeper layers of agranular frontal and motor cortices. Intermingled L5 pyramidal neurons in the $\mathrm{mPFC}$ that project to distinct cortical and subcortical targets often have different morphological and physiological properties (Morishima and Kawaguchi, 2006; Dembrow et al., 2010; Morishima et al., 2011; Otsuka and Kawaguchi, 2011). We found that L2 pyramidal neurons in the $\mathrm{mPFC}$ also have distinct targets, including the BLA and cmPFC, consistent with recent anatomy (Hirai et al., 2012). However, we observed minimal differences in dendritic morphology and intrinsic physiology of CA and CC neurons. These results imply that these neurons may be similarly capable of receiving and responding to long-range excitatory inputs, unlike those in deeper layers. They also suggest that these neurons would be difficult to distinguish based on anatomy or intrinsic physiology alone. Because of these similarities and their scarcity throughout most cortical layers, these neurons may be challenging to isolate with blind in vivo recordings.

Our initial anatomy suggested that both CA and CC neurons could receive long-range excitatory inputs from the BLA and cmPFC. Using optogenetics allowed us to demonstrate functional connections, indicating that both neurons participate in reciprocal circuits. By blocking firing with TTX and restoring release with 4-AP, our recording conditions ensured direct,
B
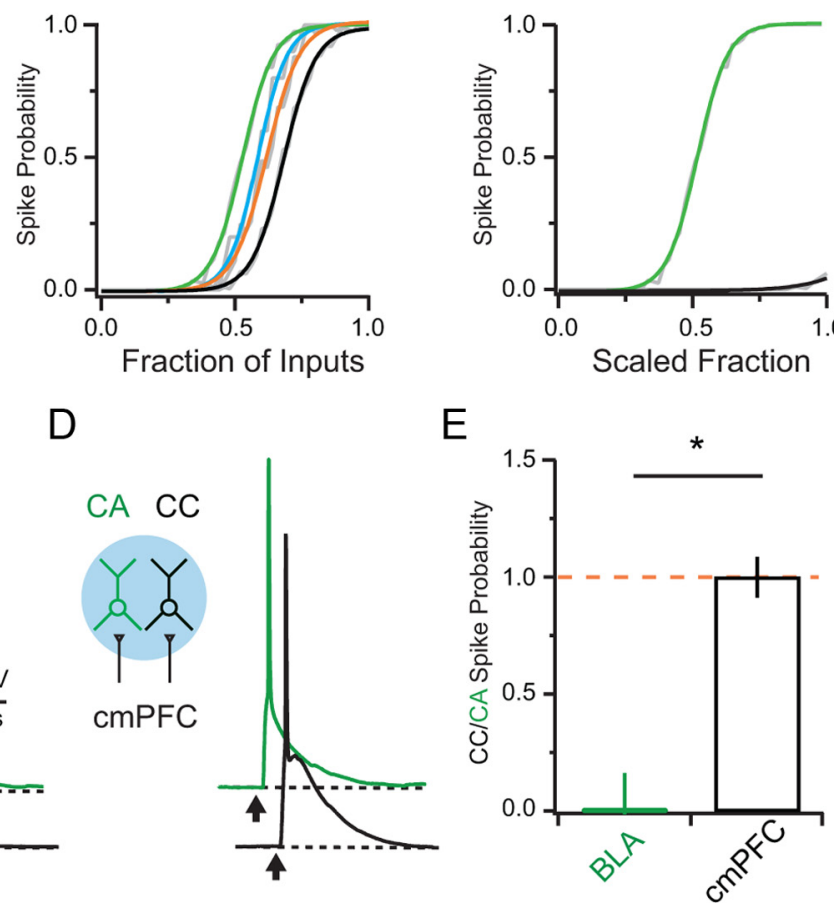

D

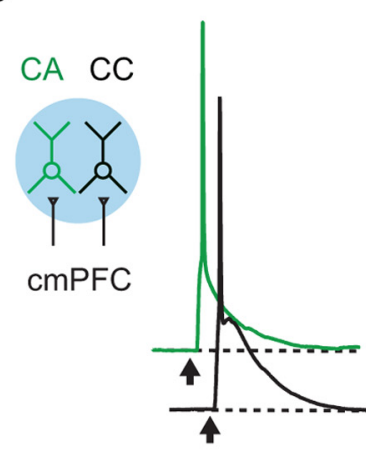

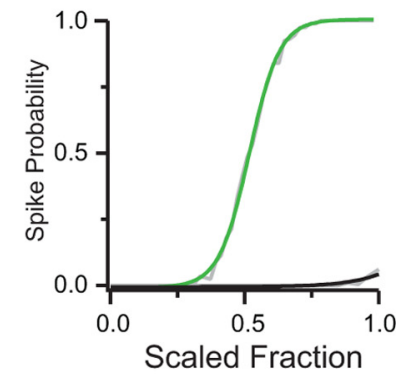

Figure 7. Differential synaptic drive in reciprocal circuits. $\boldsymbol{A}$, Left, Schematic illustrating the sampled data used for simulations. Rows indicate the neuron (CA or CC) and columns indicate the subcellular variables of spine volume (V) and dendritic distance (D). Right, Simulations of spike probability as a function of fraction of total BLA inputs. Colored sigmoidal fits correspond to the

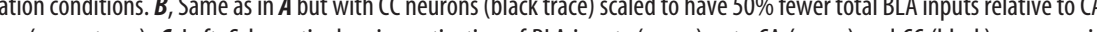
neurons evoked by BLA (green) or CmPFC (black) inputs. Asterisks indicate significance. Orange dotted line indicates a CC/CA ratio

monosynaptic connections (Petreanu et al., 2009; Cruikshank et al., 2010; Little and Carter, 2012). The amplitudes of light-evoked synaptic responses reflect a variety of experimental factors and are difficult to compare across inputs. However, taking the ratio of the responses at CA and CC neurons normalizes for this variability and allows these comparisons (MacAskill et al., 2012). Using this approach, we found that inputs from the BLA preferentially contact CA neurons over CC neurons. In contrast, inputs from the cmPFC show no preferential synaptic connectivity onto these two populations of neurons. These findings indicate that the type of projection neuron helps define the strength of its long-range connections. These results complement previous findings in other agranular cortices of long-range (Mao et al., 2011; Hooks et al., 2013) and local (Weiler et al., 2008; Anderson et al., 2010; Kiritani et al., 2012) connections onto distinct subpopulations of projection neurons. Together, these studies highlight how synaptic connectivity throughout the cortex is exquisitely organized to enable specific interactions between different cell types.

\section{Mechanisms underlying differences in synaptic strength}

One of our key findings was that BLA inputs make preferentially stronger synapses onto CA neurons. In principle, a variety of presynaptic and postsynaptic factors could contribute to stronger synaptic strength, including quantal response amplitude, probability of release, and the number of connections (Gil et al., 1999). Our Sr experiments allowed us to isolate quantal responses (Ma- 
cAskill et al., 2012) and highlighted both input and cell specificity. The larger quantal responses at CA neurons are likely attributable to the number of postsynaptic AMPARs (Matsuzaki et al., 2001), which are correlated with the size of dendritic spines (Arellano et al., 2007). These differences in quantal responses could also result from differential positioning of synapses in the dendrites (Williams and Mitchell, 2008). These experiments highlight how postsynaptic factors play an important role in determining the strength of long-range inputs.

In contrast, our paired-pulse experiments indicated minimal differences in the probability of release from BLA inputs at different neurons. Importantly, these recordings were made under conditions that preserve presynaptic APs, because direct activation of ChR2 can perturb release from the presynaptic terminal (Zhang and Oertner, 2007; Schoenenberger et al., 2011). One concern is that these monosynaptic EPSCs could be contaminated by polysynaptic activation. However, this is unlikely in our experiments, because pulse durations were kept short (under 2 $\mathrm{ms}$ ) and the differences in EPSC amplitudes are similar to widefield stimulation. Although these PPR experiments are only a first step in analyzing presynaptic differences at these synapses, our findings suggest that other factors determine the strength of BLA inputs onto CA and CC neurons.

The observed differences in quantal response amplitude could not fully account for the large disparity in compound response amplitude. An additional factor that could influence synaptic strength is the number of synaptic connections (Cruikshank et al., 2007; Bagnall et al., 2011; Franks et al., 2011). To assess this possibility, we used two-photon mapping to directly measure synapse density at spines in dendritic segments. This technique provides a readout of functional connectivity at the level of individual spines (Little and Carter, 2012; MacAskill et al., 2012). It is conceptually similar to mapping experiments used to identify functional inputs onto neurons in vivo (Chen et al., 2011). Our two-photon mapping experiments revealed that BLA inputs are twice as likely to make connections onto CA neurons. These experiments also showed differences in subcellular targeting, with BLA inputs contacting larger and more proximal spines at CA neurons than nearby $\mathrm{CC}$ neurons. These results demonstrate how multiple synaptic factors distinguish BLA connections onto different projection neurons.

In other neurons, synaptic strength is influenced by dendritic location (Williams and Stuart, 2002), spine volume (Matsuzaki et al., 2001; Arellano et al., 2007), or their combination (Richardson et al., 2009; MacAskill et al., 2012). These subcellular properties can also strongly influence the strength of excitatory inputs onto L2 pyramidal neurons (Little and Carter, 2012). Using a model that incorporated our previous two-photon uncaging results, we found that spine and dendrite targeting causes BLA inputs to be stronger at CA neurons. However, synapse density also proved critical in determining overall synaptic strength and drive at these neurons. Thus, a combination of factors allows a common afferent to differentially excite nearby cortical projection neurons that are otherwise similar in their dendritic anatomy and intrinsic physiology. In the future, it will be interesting to determine how these factors are changed in fear conditioning and other emotional behaviors that can alter interactions between $\mathrm{mPFC}$ and BLA.

\section{Functional roles of synaptic connections between mPFC and BLA}

The $\mathrm{mPFC}$ governs a range of higher-level behaviors, including working memory and attention (Goldman-Rakic, 1995; Miller,
2000; Fuster, 2001). One of the best-characterized functions of the mPFC is the control of emotional behaviors, which are thought to critically depend on long-range interactions with the BLA (LeDoux, 2000; Maren and Quirk, 2004). Activity within the prelimbic mPFC correlates with the expression of conditioned fear (Burgos-Robles et al., 2009). Moreover, pharmacological inactivation of the prelimbic mPFC prevents the expression of this behavior (Corcoran and Quirk, 2007). Distinct populations of neurons in the BLA project to the mPFC and play unique functional roles during the learning and extinction of conditioned fear (Herry et al., 2008). Moreover, activating the BLA may enable sustained firing of $\mathrm{mPFC}$ neurons during fear conditioning (Sotres-Bayon and Quirk, 2010; Sotres-Bayon et al., 2012). Although indirect networks could mediate these interactions, our findings highlight the presence of direct connections between the mPFC and BLA. Equivalent closed-loop neural architectures are proposed to enhance the gain of other local and long-range circuits (Douglas et al., 1995; Mongillo et al., 2008). In the future, it will be interesting to examine how these long-range interactions are influenced by local connections within and between different layers of the MPFC.

\section{References}

Anderson CT, Sheets PL, Kiritani T, Shepherd GM (2010) Sublayer-specific microcircuits of corticospinal and corticostriatal neurons in motor cortex. Nat Neurosci 13:739-744. CrossRef Medline

Arellano JI, Benavides-Piccione R, Defelipe J, Yuste R (2007) Ultrastructure of dendritic spines: correlation between synaptic and spine morphologies. Front Neurosci 1:131-143. CrossRef Medline

Bacon SJ, Headlam AJ, Gabbott PL, Smith AD (1996) Amygdala input to medial prefrontal cortex (mPFC) in the rat: a light and electron microscope study. Brain Res 720:211-219. CrossRef Medline

Bagnall MW, Hull C, Bushong EA, Ellisman MH, Scanziani M (2011) Multiple clusters of release sites formed by individual thalamic afferents onto cortical interneurons ensure reliable transmission. Neuron 71:180-194. CrossRef Medline

Brown SP, Hestrin S (2009) Intracortical circuits of pyramidal neurons reflect their long-range axonal targets. Nature 457:1133-1136. CrossRef Medline

Burgos-Robles A, Vidal-Gonzalez I, Quirk GJ (2009) Sustained conditioned responses in prelimbic prefrontal neurons are correlated with fear expression and extinction failure. J Neurosci 29:8474-8482. CrossRef Medline

Chalifoux JR, Carter AG (2010) GABAB receptors modulate NMDA receptor calcium signals in dendritic spines. Neuron 66:101-113. CrossRef Medline

Chalifoux JR, Carter AG (2011) $\mathrm{GABA}_{\mathrm{B}}$ receptor modulation of voltagesensitive calcium channels in spines and dendrites. J Neurosci 31:42214232. CrossRef Medline

Chen X, Leischner U, Rochefort NL, Nelken I, Konnerth A (2011) Functional mapping of single spines in cortical neurons in vivo. Nature 475: 501-505. CrossRef Medline

Corcoran KA, Quirk GJ (2007) Activity in prelimbic cortex is necessary for the expression of learned, but not innate, fears. J Neurosci 27:840-844. CrossRef Medline

Cruikshank SJ, Lewis TJ, Connors BW (2007) Synaptic basis for intense thalamocortical activation of feedforward inhibitory cells in neocortex. Nat Neurosci 10:462-468. CrossRef Medline

Cruikshank SJ, Urabe H, Nurmikko AV, Connors BW (2010) Pathwayspecific feedforward circuits between thalamus and neocortex revealed by selective optical stimulation of axons. Neuron 65:230-245. CrossRef Medline

Dembrow NC, Chitwood RA, Johnston D (2010) Projection-specific neuromodulation of medial prefrontal cortex neurons. J Neurosci 30:1692216937. CrossRef Medline

Douglas RJ, Martin KAC (2004) Neuronal circuits of the neocortex. Annu Rev Neurosci 27:419-451. CrossRef Medline

Douglas RJ, Koch C, Mahowald M, Martin KA, Suarez HH (1995) Recurrent excitation in neocortical circuits. Science 269:981-985. CrossRef Medline 
Dumitriu D, Rodriguez A, Morrison JH (2011) High-throughput, detailed, cell-specific neuroanatomy of dendritic spines using microinjection and confocal microscopy. Nat Protoc 6:1391-1411. CrossRef Medline

Egan MF, Weinberger DR (1997) Neurobiology of schizophrenia. Curr Opin Neurobiol 7:701-707. CrossRef Medline

Franks KM, Russo MJ, Sosulski DL, Mulligan AA, Siegelbaum SA, Axel R (2011) Recurrent circuitry dynamically shapes the activation of piriform cortex. Neuron 72:49-56. CrossRef Medline

Fuster JM (2001) The prefrontal cortex-an update: time is of the essence. Neuron 30:319-333. CrossRef Medline

Gabbott PL, Warner TA, Jays PR, Salway P, Busby SJ (2005) Prefrontal cortex in the rat: projections to subcortical autonomic, motor, and limbic centers. J Comp Neurol 492:145-177. CrossRef Medline

Gil Z, Connors BW, Amitai Y (1999) Efficacy of thalamocortical and intracortical synaptic connections: quanta, innervation, and reliability. Neuron 23:385-397. CrossRef Medline

Goda Y, Stevens CF (1994) Two components of transmitter release at a central synapse. Proc Natl Acad Sci U S A 91:12942-12946. CrossRef Medline

Goldman-Rakic PS (1995) Cellular basis of working memory. Neuron 14: 477-485. CrossRef Medline

Hattox AM, Nelson SB (2007) Layer V neurons in mouse cortex projecting to different targets have distinct physiological properties. J Neurophysiol 98:3330-3340. CrossRef Medline

Herry C, Ciocchi S, Senn V, Demmou L, Müller C, Lüthi A (2008) Switching on and off fear by distinct neuronal circuits. Nature 454:600-606. CrossRef Medline

Hirai Y, Morishima M, Karube F, Kawaguchi Y (2012) Specialized cortical subnetworks differentially connect frontal cortex to parahippocampal areas. J Neurosci 32:1898-1913. CrossRef Medline

Hooks BM, Hires SA, Zhang YX, Huber D, Petreanu L, Svoboda K, Shepherd GM (2011) Laminar analysis of excitatory local circuits in vibrissal motor and sensory cortical areas. PLoS Biol 9:e1000572. CrossRef Medline

Hooks BM, Mao T, Gutnisky DA, Yamawaki N, Svoboda K, Shepherd GM (2013) Organization of cortical and thalamic input to pyramidal neurons in mouse motor cortex. J Neurosci 33:748-760. CrossRef Medline

Hoover WB, Vertes RP (2007) Anatomical analysis of afferent projections to the medial prefrontal cortex in the rat. Brain Struct Funct 212:149-179. CrossRef Medline

Hull C, Isaacson JS, Scanziani M (2009) Postsynaptic mechanisms govern the differential excitation of cortical neurons by thalamic inputs. J Neurosci 29:9127-9136. CrossRef Medline

Kampa BM, Letzkus JJ, Stuart GJ (2006) Cortical feed-forward networks for binding different streams of sensory information. Nat Neurosci 9:1472-1473. CrossRef Medline

Kiritani T, Wickersham IR, Seung HS, Shepherd GM (2012) Hierarchical connectivity and connection-specific dynamics in the corticospinalcorticostriatal microcircuit in mouse motor cortex. J Neurosci 32:4992-5001. CrossRef Medline

Le Bé JV, Silberberg G, Wang Y, Markram H (2007) Morphological, electrophysiological, and synaptic properties of corticocallosal pyramidal cells in the neonatal rat neocortex. Cereb Cortex 17:2204-2213. CrossRef Medline

LeDoux JE (2000) Emotion circuits in the brain. Annu Rev Neurosci 23: 155-184. CrossRef Medline

Little JP, Carter AG (2012) Subcellular synaptic connectivity of layer 2 pyramidal neurons in the medial prefrontal cortex. J Neurosci 32: 12808-12819. CrossRef Medline

MacAskill AF, Little JP, Cassel JM, Carter AG (2012) Subcellular connectivity underlies pathway-specific signaling in the nucleus accumbens. Nat Neurosci 15:1624-1626. CrossRef Medline
Mao T, Kusefoglu D, Hooks BM, Huber D, Petreanu L, Svoboda K (2011) Long-range neuronal circuits underlying the interaction between sensory and motor cortex. Neuron 72:111-123. CrossRef Medline

Maren S, Quirk GJ (2004) Neuronal signalling of fear memory. Nat Rev Neurosci 5:844-852. CrossRef Medline

Matsuzaki M, Ellis-Davies GC, Nemoto T, Miyashita Y, Iino M, Kasai H (2001) Dendritic spine geometry is critical for AMPA receptor expression in hippocampal CA1 pyramidal neurons. Nat Neurosci 4:1086-1092. CrossRef Medline

McDonald AJ (1991) Organization of amygdaloid projections to the prefrontal cortex and associated striatum in the rat. Neuroscience 44:1-14. CrossRef Medline

McDonald AJ, Mascagni F, Guo L (1996) Projections of the medial and lateral prefrontal cortices to the amygdala: a Phaseolus vulgaris leucoagglutinin study in the rat. Neuroscience 71:55-75. CrossRef Medline

Miller EK (2000) The prefrontal cortex and cognitive control. Nat Rev Neurosci 1:59-65. CrossRef Medline

Mongillo G, Barak O, Tsodyks M (2008) Synaptic theory of working memory. Science 319:1543-1546. CrossRef Medline

Morishima M, Kawaguchi Y (2006) Recurrent connection patterns of corticostriatal pyramidal cells in frontal cortex. J Neurosci 26:4394-4405. CrossRef Medline

Morishima M, Morita K, Kubota Y, Kawaguchi Y (2011) Highly differentiated projection-specific cortical subnetworks. J Neurosci 31:10380-10391. CrossRef Medline

Otsuka T, Kawaguchi Y (2011) Cell diversity and connection specificity between callosal projection neurons in the frontal cortex. J Neurosci 31: 3862-3870. CrossRef Medline

Petreanu L, Huber D, Sobczyk A, Svoboda K (2007) Channelrhodopsin-2assisted circuit mapping of long-range callosal projections. Nat Neurosci 10:663-668. CrossRef Medline

Petreanu L, Mao T, Sternson SM, Svoboda K (2009) The subcellular organization of neocortical excitatory connections. Nature 457:1142-1145. CrossRef Medline

Richardson RJ, Blundon JA, Bayazitov IT, Zakharenko SS (2009) Connectivity patterns revealed by mapping of active inputs on dendrites of thalamorecipient neurons in the auditory cortex. J Neurosci 29:6406-6417. CrossRef Medline

Schoenenberger P, Schärer YPZ, Oertner TG (2011) Channelrhodopsin as a tool to investigate synaptic transmission and plasticity. Exp Physiol 96: 34-39. CrossRef Medline

Sesack SR, Deutch AY, Roth RH, Bunney BS (1989) Topographical organization of the efferent projections of the medial prefrontal cortex in the rat: an anterograde tract-tracing study with Phaseolus vulgaris leucoagglutinin. J Comp Neurol 290:213-242. CrossRef Medline

Sotres-Bayon F, Quirk GJ (2010) Prefrontal control of fear: more than just extinction. Curr Opin Neurobiol 20:231-235. CrossRef Medline

Sotres-Bayon F, Sierra-Mercado D, Pardilla-Delgado E, Quirk GJ (2012) Gating of fear in prelimbic cortex by hippocampal and amygdala inputs. Neuron 76:804-812. CrossRef Medline

Weiler N, Wood L, Yu J, Solla SA, Shepherd GM (2008) Top-down laminar organization of the excitatory network in motor cortex. Nat Neurosci 11:360-366. CrossRef Medline

Williams SR, Mitchell SJ (2008) Direct measurement of somatic voltage clamp errors in central neurons. Nat Neurosci 11:790-798. CrossRef Medline

Williams SR, Stuart GJ (2002) Dependence of EPSP efficacy on synapse location in neocortical pyramidal neurons. Science 295:1907-1910. CrossRef Medline

Zhang YP, Oertner TG (2007) Optical induction of synaptic plasticity using a light-sensitive channel. Nat Methods 4:139-141. CrossRef Medline 